\title{
MEMÓRIAS DE PROFESSORES: UMA EXPERIÊNCIA DE PESQUISA NA FORMAÇÃO DE PROFESSORES DE ENSINO SUPERIOR
}

\section{Teachers memories: a research experience on hig education teacher development}

Maria de Lourdes Rocha de Lima ${ }^{1}$

\section{Resumo}

Neste trabalho buscamos aprofundar a leitura teórica das memórias de professores mais marcantes, fazendo estudos sobre a socialização profissional do professor universitário conforme as pesquisas feitas por Garcia (1999), associando-os aos estudos de saberes de professores elaborados por Tardif (2002). Partimos do pressuposto de que as memórias dos professores selecionados pelos alunos de pós-graduação deveriam expressar certas habilidades básicas, para lidar com os processos de ensino e aprendizagem, constituindo assim o processo de socialização prévia. Nesta perspectiva os saberes experenciais do professor não se baseiam unicamente na prática de sala de aula, mas decorreriam, em grande parte, das pré-concepções do ensino e da aprendizagem herdadas da história escolar. Concluímos que as memórias de professores mais marcantes, os saberes docentes e a socialização profissional são processos sociais inter-relacionados e são indissociáveis como formação docente.

Palavras chaves: Memórias; Socialização profissional; Saberes docentes.

Doutora em Educação pela FE-USP, professora do Programa de Pós-graduação da Faculdade de Educação da Universidade Federal de Minas Gerais. mlourdes@fae.ufmg.br 


\section{Abstract}

On this work, we try to get to the bottom of the theoretical reading of the most meaningful teachers memories, studying about the professional socialization of the academic teacher, such as the researches done by Garcia (1999), and joining them to a teacher knowledge selected Tardiff (2002). Based on conjectures of teachers memories selected by postgraduate students, should express such basic skills in dealing with the teaching leaming process, making this way, a previous socialization process. Into this perspective, a personal teacher experiential knowledge is not based only in classroom practices, but as a consequence, mostly of the previous conceptions in a teaching and learning process, inherited from the school history. We conclude that, the most meaningful memories, their academic knowledge, and the professional socialization, are interrelated social process and inseparable in an academic development.

Keywords: Memories; Professional Socialization; Academic Knowledge.

\section{Introdução}

Nesse texto venho propor o estabelecimento de uma nova leitura sobre a formação do professor de ensino superior, com base nos saberes que ele vem acumulando pela trajetória de sua vida escolar, conhecimento este aprendido com os professores que lhe marcaram pela vida estudantil, seja no sentido positivo ou negativo, no qual iniciaram o seu respectivo processo de socialização profissional.

É comum encontrarmos professores de graduação nos cursos superiores que não tiveram nenhuma formação pedagógica voltada para a sala de aula, sendo que seus cursos de mestrado ou doutorado só lhes permitiram uma formação em conteúdos da área específica e em pesquisa científica.

No entanto, esses professores enfrentam o trabalho docente e atuam, às vezes, até com sucesso pelos caminhos da docência, num jogo de ensaio e erro no campo de inúmeras incertezas, lembrando-se de como seus professores anteriores se saíam em situações similares.

É com base nessas situações de ensino que estudos referentes a memórias de professores mais marcantes em sua trajetória escolar têm sentido e assumem significado ontológico e epistemológico e relação às práticas de formação de professores no ensino superior.

Assim, quanto mais anos de escolaridade tem o professor, maior o acúmulo de modelos de professores ele tem em sua vida pessoal e pode fazer uso improvisado destes referidos modelos em sua prática pedagógica. 
Memórias de professores: uma experiência de pesquisa na formação de professores de ensino superior

\section{Situando teoricamente o objeto de estudo}

Desde 1985, venho estudando memórias de professores mais marcantes e cada vez mais vou confirmando minhas descobertas sobre as habilidades pedagógicas que o professor de ensino superior já traz para o exercício do magistério, mesmo quando não tem nenhuma formação pedagógica anterior.

O objetivo dos primeiros estudos de memórias de professores era explicar as relações destas memórias com as tendências das teorias de ensino.

Em 1995, emergiu novo eixo desses estudos, conforme tese de doutorado por nós elaborada, na FEUSP, sob a orientação da Prof. Dra. Marli André, quando concluímos que as memórias de professores mais marcantes constituem saberes docentes que vão se constituindo no exercício de sua prática a partir das lembranças de professores.

Uma das conclusões desse estudo (LMA, 1995, p. 144 - 145) é que 0 professor-aluno tem na memória as lembranças das práticas escolares que viveu e na qual organizou suas experiências e seus saberes docentes. Assim, na prática de sala de aula, nos momentos de conflito sobre como agir, ele traz o saber de sua trajetória escolar e vai reconstituindo novos saberes para resolver os problemas, que se lhe apresentam na cena de aula. Esses saberes vão sendo validados nos encontros coletivos de professores, que objetivam discutir, avaliar e fazer a reflexão crítica da prática.

Os dados dessa pesquisa registram também que a memória de professores mais marcantes constitui um conhecimento conservador que 0 alunoprofessor traz para a sua prática docente e este conhecimento resiste às novas formas de fazer na escola atual.

No presente trabalho, buscamos aprofundar a leitura teórica das memórias de professores mais marcantes, fazendo estudos sobre a socialização profissional do professor universitário, expondo as formas como esse sujeito experimenta e constrói seu mundo, suas experiências, crenças e teorias, baseado nas vivências e convivências que teve com seus professores no tempo de seu processo de escolarização, isto é, associando os estudos de socialização do professor Garcia (1999) aos estudos de saberes de professores, Tardif (2002).

Iniciamos nossa busca pelos estudos de Ludke (1996) por meio de seu artigo intitulado "Sobre a socialização profissional de professores", que indica que a formação de profissionais no primeiro momento focaliza a influência da escola e de sua função na aprendizagem de papéis sociais.

Afirma Ludke apoiando-se em Dubar (1991) que a socialização profissional consiste em construir sua identidade social e profissional pelo jogo das transações biográficas e relacionais. 
O trabalho de Nunes (2002) analisa que seu objeto de estudo é o processo de aprender e ensinar situado no âmbito da socialização. A autora conclui que existem três estratégias de aprendizagem da profissão que são: aprendizagem por observação, dialógica e por ensaio e erro.

Os estudos de Ludke (1996) e de Nunes (2002) estão entre os trabalhos brasileiros que adotam a abordagem da socialização do professor como base compreensiva de aprendizagem da profissão e explicativa do processo de aprender e ensinar.

Outros estudos internacionais que se voltam para a socialização profissional ou que fornecem elementos importantes para a compreensão da aprendizagem da profissão, seja no percurso da escolarização, ou no processo de formação inicial, ou no exercício profissional, são os de Lortie (1985), Zeichner (1985), Lucas (1986), Zeichner e Gore (1990), Dubar (1991) e Garcia (1999).

$\mathrm{O}$ professor, à medida que adquire a cultura própria de um grupo, passa a fazer parte desse grupo. Assim a socialização pode ser compreendida como o meio de a pessoa aprender a interiorizar os elementos socioculturais de seu ambiente, das pessoas e experiências que consideram significativas, integrando-as em sua personalidade e se adaptando em seu entorno, segundo Lucas (1986).

"A socialização do professor universitário não ocorre apenas nos primeiros anos de docência e de investigação. Existe uma socialização prévia durante os anos em que o futuro professor foi aluno, observou professores a ensinar, colaborou com algum professor na realização da investigação. Durante esse período os professores aprendem formas de comportamento, estilos de ensino" conforme assinala Garcia (1999, p. 250).

É a este último estudo de socialização profissional que no presente estudo queremos juntar nossas observações e experiências sistematizadas sobre memórias de professores, hipotetizando que o resgate das referidas memórias de professores são formas de socialização prévia, que integram ao desempenho do professor os respectivos estilos e formas de comportamento dos seus professores durante o tempo em que o futuro professor fora aluno.

Portanto, o presente trabalho busca registrar memórias de professores mais marcantes de alunos de cursos de pós-graduação stricto sensu de diversas áreas cientificas: Saúde, Tecnologias, Humanas e Sociais de forma a encontrar alguma relação entre os saberes inseridos em tais lembranças de professores e os processos de socialização profissional em docência.

Partimos do pressuposto de que as memórias dos professores mais marcantes de ensino superior selecionados pelos alunos de pós-graduação deveriam expressar certas habilidades básicas, para lidar com os processos de ensino e aprendizagem, e, que tais habilidades, provavelmente, eram aprendidas como saberes docentes, durante o tempo em que tais alunos eram estu- 
dantes de curso de graduação, constituindo assim o processo de socialização prévia.

Estamos trabalhando, portanto, saber docente na concepção apresentada por Tardif que situa que a docência compõe-se de vários saberes. Segundo Tardif (2002, p. 47), os saberes docentes são disciplinares, curriculares, profissionais e experenciais e implicam num processo de aprendizagem e de formação.

Os saberes profissionais dos professores são, portanto, plurais, heterogêneos, porque trazem à tona, no próprio exercício do trabalho, a socialização profissional, ou seja, os conhecimentos e manifestações do saber-fazer e do saber-ser, provenientes de fontes variadas (GARCIA, 1999).

Trabalhar não é exclusivamente transformar um objeto ou situação numa outra coisa, sua identidade carrega as marcas da sua própria atividade e uma boa parte de sua existência é caracterizada por sua atuação profissional. O trabalho é aprendido pela imersão no ambiente familiar e social.

Assim, concebemos as memórias de professores como sendo saberes do tipo experenciais, sociais, que se manifestam no saber-fazer e no saber-ser, em sala de aula, segundo Tardif (2002, p. 48). Tais saberes são provenientes de fontes variadas, que significam uma das formas de socialização prévia profissional de professores, referente à fase em que o futuro professor fora aluno, segundo Garcia (1999, p. 250).

\section{Metodologia do estudo}

Reunimos as memórias de professores mais marcantes de alunos do curso de pós-graduação stricto sensu, matriculados na disciplina Didática do Ensino Superior, da área Tecnológica (Engenharia, Informática) e Saúde (Medicina, Fisioterapia, Odontologia, Farmácia e Educação Física), compreendendo processos de socialização primária, que se referem às aprendizagens que os alunos vão formando devido ao convívio com experiências pedagógicas de seus professores durante a trajetória da escolaridade.

A metodologia investigativa foi representada por um relato no qual o pós-graduando apresentava três professores que lhe marcaram pelas habilidades de ensino, que serviam de exemplo para a vida profissional futura.

Este estudo exploratónio descritivo pretende qualificar diferenças entre grupos de profissionais, sem usar estatísticas para assinalar as referidas diferenças significativas entre os saberes de professores marcantes que influenciaram as memórias, as representações e as crenças destes citados alunos durante o tempo do curso de graduação. 


\section{Os dados sobre as memórias mais marcantes} marcantes.

Apresentamos a seguir os dados das memórias de professores mais

1. Área Tecnológica (alunos do Curso de Mestrado e Doutorado em Engenharia e Ciência da Informação)

\section{Professor A}

"A matéria era muito difícil e muito abstrata. Exigia raciocínio matemático e muita imaginação para entender os movimentos atômicos. Porém o professor conseguia quebrar a dificuldade e fazer com que todas as pessoas entendessem e tomassem gosto."

\section{Professor I}

"O professor era superintendente de produção da antiga Mannesmann, usina produtora de aço e ele ministrava aulas de Siderurgia I e II. Tinha um ótimo conhecimento técnico e sua principal habilidade era a capacidade de integrar teoria e prática. Os alunos sentiam que as aulas tinham uma prática imediata e se motivavam em aprender."

\section{Professor J}

"O professor tinha facilidade de explicar os conceitos de Termodinâmica Metalúrgica de forma extremamente didática e simples, motivando o aprendizado. Tinha também facilidade de integrar teoria e prática, passando dos conceitos à aplicação com naturalidade."

\section{Professor K}

"O professor ensina Contabilidade e Custos. É uma disciplina que exige muita atenção e muitos cálculos e poucos alunos a apreciam. Ele solucionou essa dificuldade ensinando o assunto usando exemplos simples do dia-a-dia. Ele ensinava Contabilidade usando a economia doméstica como exemplo, mas sem banalizar o assunto. O resultado é que todos entendem o processo e se motivam a aprender a analisar e efetuar balanços contábeis complexos sem dificuldades."

Observamos, em todas as falas de alunos, que eles se referem de forma positiva sobre seus professores de graduação, principalmente, porque conseguiram aprender a disciplina, seja por meio da relação teoria e prática, seja pelas analogias entre matérias simples com matéria complexa, seja pela relação entre assuntos abstratos e concretos, ou usando metodologias especiais como grupo de discussão. 
Segundo Tardif (2002, p. 68), chamamos de trajetória profissional como estudaram Carter e Doyle (1996); Raymond, (1998), o que uma boa parte dos professores sabe sobre o ensino, sobre os papéis do professor e sobre como ensinar, que provém de sua própria história de vida, principalmente, de sua socialização prévia enquanto aluno.

Os professores são trabalhadores que ficaram imersos em seu lugar de trabalho durante aproximadamente 16 anos antes de começarem a trabalhar. Essa imersão se expressa em toda uma bagagem de conhecimentos anteriores de crenças, de representações e de ações sobre a prática docente. Esse legado da socialização permanece forte e estável através do tempo.

Esses saberes adquiridos durante a trajetória pré-profissional, quando ocorre a socialização escolar, têm um peso importante na compreensão do saber-fazer e do saber - ser, que serão utilizados posteriormente no próprio exercício do magistério.

Desta forma, pode-se dizer que uma parte importante da competência profissional dos professores tem raízes em sua história de vida, quando se formam as crenças, as representações, os hábitos práticos e as rotinas de ação (RAYMOND et al., 1993).

Área de Saúde (alunos dos Cursos de Mestrado e Doutorado em Medicina, Odontologia, Terapia Ocupacional, Farmácia e Educação Física).

\section{Professor L}

"Este professor ministrou a disciplina Filosofia do Esforço, que era dada de forma tradicional, em que após as exposições ele nos passava uma série de exercícios matemáticos para resolvermos. A partir daí tínhamos grupos de discussão entre artigos científicos voltados para nossos estudos. O professor estimulava o raciocínio crítico e nos ensinava a sermos verdadeiros pesquisadores. Desta forma desenvolvi meu espírito crítico e a cada dia me interessei mais pela pesquisa e pelo ensino."

\section{Professor M}

"A professora tinha grande conhecimento de Cinesiologia, bem como de outras áreas afins. Possuía grande tranqüilidade para ministrar aulas e utilizava transparências. Levantava questionamentos, estimulava a participação dos alunos em sala de aula, apresentava exercícios práticos para facilitar nosso entendimento da teoria. Estimulava a participação de todos em grupos de discussão sobre um tema, que dois alunos escolhiam sobre o caso de seus pacientes. Era necessária a busca de artigos científicos atuais para a discussão . Auxiliava-nos avaliando alguns pacientes conosco e discutindo as possíveis intervenções e o acompanhamento da conduta com o paciente." 


\section{Professor P}

"O professor de Anatomia ministrava suas aulas com grande prazer. Ficava estampado em sua face o gosto pela docência. Algumas aulas eram expositivas com muita participação da turma. Em outras aulas utilizava exemplos e casos clínicos. As aulas passavam sem que o aluno percebesse. Apresentava na primeira aula regras, plano de curso e cronograma. Sua didática era excelente, com nível de cobrança elevado, porém sem pressão sobre o aluno."

\section{Professor Q}

"O professor de Clínica Médica foi marcante em minha formação integral como médico, pois dotado de uma ética profissional ímpar, foi soberano em transmitir uma visão integral de Medicina, que envolvia o conceito de integralidade para com os pacientes, a atenção às suas queixas e demandas, tratando-os não como meros portadores de uma patologia, e, sim, como pessoas, fazendo o estudo detalhado da semilogia médica, sempre estimulando a atualização nesses temas, com o intuito de sempre tomar condutas coerentes e fundamentais ao ensino."

Analisando esses relatos da área da saúde, distinguimos como os alunos aprendem com seus professores processos de ensino, que os orientam a uma participação eficaz nas aulas, iniciação à pesquisa, discussão de casos clínicos, estudo de bibliografia complementar às aulas, discussão de temas científicos e a forma integral de tratar o paciente como sujeito histórico. Valorizaram, também, a conduta ética dos professores no trato com os pacientes e como as habilidades deles com o ensino e a pesquisa os arrastam para trabalhar no campo.

As experiências escolares anteriores e as relações determinantes com professores contribuem para modelar a identidade pessoal dos professores e seu conhecimento prático.

Segundo Tardif (2002, p. 78 -79)

Os resultados obtidos nas pesquisas (Lessard \& Tardif, 1996; Tardif \& Lessard, 2002; Raymond et alii, 1993) demarcam a importância da história de vida dos professores, em particular, a de sua socialização escolar, tanto no que diz respeito à escolha da carreira e ao estilo de ensino, quanto à relação afetiva e personalizada no trabalho... Eles indicam, finalmente, que o tempo de aprendizagem do trabalho não se limita à duração da vida profissional, mas inclui também a existência pessoal dos professores, os quais, de certo modo, aprenderam seu ofício antes de iniciá-lo.

Ao longo das histórias de vida pessoal e escolar, supõe-se que o professor interioniza certo número de conhecimento, de competências, de crenças, 
de valores. Nesta perspectiva, os saberes experenciais do professor não se baseiam unicamente na prática de sala de aula, mas decorriam, em grande parte, das preconcepções do ensino e da aprendizagem herdada da história escolar.

\section{À guisa de conclusões}

De acordo com Tardif (2002, p. 102) situando os trabalhos de Raymond et al. (1993); de Lessard e Tardif (1996) e de Tardif e Lessard (2000), afirmamos que os saberes profissionais dos professores são plurais, mas também temporais, ou seja, adquiridos por certos processos de aprendizagem de socialização, que atravessam tanto a história de vida quanto a carreira.

Os saberes que servem de base para o ensino, isto é, os fundamentos do saber ensinar, não se reduzem a um sistema cognitivo. Na realidade os fundamentos do ensino são, a um só tempo, existenciais, sociais e pragmáticos.

Segundo Tardif (2002, p. 103), os fundamentos do ensino são existenciais no sentido de que o professor não é somente um sujeito epistêmico, que se coloca diante do mundo numa relação estrita de conhecimento, mas ele é um ser-no-mundo, um "Dasein" (HEIDEGGER, 1927). Ele é uma pessoa comprometida com e por sua própria história pessoal, familiar, escolar, social. Ainda apresenta Tardif (2002, p. 104) que os

Fundamentos do ensino são sociais, porque os saberes profissionais são plurais, provêm de fontes so ciais diversas (família, escola, universidade, etc.) e são adquiridos em tempos sociais diferentes: tempo da infância, da escola, da formação profissional, do ingresso na profissão, da carreira... são sociais também, porque, em certos casos, são produzidos e legitimados por grupos sociais...

Finalmente, são pragmáticos, pois os saberes que servem de base ao ensino estão intimamente ligados tanto ao trabalho quanto à pessoa do trabalhador.

É impossível compreender a questão da socialização dos professores sem inseri-la, imediatamente, na história dos próprios atores, de suas ações, projetos e desenvolvimento profissional.

Essa historicidade se expressa e se exprime nos saberes profissionais dos professores, tanto nos saberes experenciais adquiridos no início da carreira, como nos saberes adquiridos nos processos anteriores (familiar, escolar e universitária).

Finalmente, as memórias dos professores mais marcantes expressam como os alunos aprendem com seus mestres as formas de fazer o ensino e de ser professor, a partir dos processos de socialização com os quais convivem na sua história escolar como alunos. 
Concluímos que as memórias de professores mais marcantes, os saberes docentes e a socialização profissional são processos que na prática docente estão inter-relacionados e são indissociáveis como formação docente.

\section{Referências}

DUBAR, C. A socialização: construção de identidades sociais e profissionais. Portugal. Porto, 1997.

GARCIA, C. Marcelo. Formação de professores: para uma mudança educativa. Portugal. Porto, 1999.

LMA, M. L R. A memória educativa no projeto de formação de professores do ensino superior: o fazer é sobretudo criação. Tese (Doutorado)FEUSP, São Paulo, 1995

LORTIE, D. C. Schooltheacher: a sociological study. Chicago: University of Chicago, 1975.

LUCAS, A. El processo de socializa: um enfoque sociológico. Revista Española de Pedagogia, n. 173, p. 357 - 370, 1986.

LUDKE, M. Os professores e sua socialização profissional. In: REALI, A.M.M.R, MIZUKAMI, M.G.N. (Org.). Formação de professores: tendências atuais. São Carlos: EDUFSCAR, 1996. p. 25 - 46.

NUNES, J. B. C. Aprendendo a ensinar: um estudo desde a perspectiva da socialização docente. ANPED, Caxambu, CD Rom, 2002.

RAYMOND, D. et al. Savoirs pré-professionnels et formation fundamentale: approche autobiographique. In: GAUTHIER, C., MEL - LOUKI, M.; TARDIF, M. (éds). Le savoir des euseignants: unité et diversité. Montreal: Logiques, 1993. p. 137 - 168.

TARDIF, Maurice. Saberes docentes e formação profissional. Petrópolis: Vozes, 2002.

ZEICHNER, K. M. Dialéctica de la socializatión del professor. Revista de Educatión, Madri, n. 277, p. 95 - 123, 1985.

ZEICHNER, K. M. ; Gore, J. M. Theacher socialization. In: Houston, W. R. (Ed.) Handbook of research on teacher education. New York: Macmillan, 1990. p. $329-348$. 